\title{
Protrusion of the lung apex through Sibson's fascia in infancy
}

\author{
MICHAEL GRUNEBAUM ${ }^{1}$ AND N. THORNE GRISCOM
}

From the Department of Radiology, The Children's Hospital Medical Center and Harvard Medical School, Boston, Massachusetts 02115, USA

Grunebaum, M., and Griscom, N. T. (1978). Thorax, 33, 290-294. Protrusion of the lung apex through Sibson's fascia in infancy. Apical 'herniation' of the lung is an unusual protrusion of the lung and its pleural coverings through the superior aperture of the thorax. It is supposedly caused by weakness of Sibson's fascia. The phenomenon is an anatomical variation and not a disease entity; however, it must be recognised in order to avoid inappropriate surgery. The condition apparently disappears spontaneously with growth.

Protrusion of the lung parenchyma into the neck is uncommon (Reinhart and Hermel, 1951; Munnell, 1968), especially in children (Bronsther et al., 1968; Thompson, 1976). Descriptions of this phenomenon during the first year of life are rare (Palazzo and Garrett, 1951; Cunningham and Peters, 1969). Of the eight patients with protrusion of the apex of the lung through Sibson's fascia $^{2}$ seen at this hospital in the last 30 years, only three were below the age of 1 year. Those three, in all of whom the protrusion later disappeared, are the subject of this report.

\section{Case histories}

\section{CASE 1}

A 3-month-old boy had increasing respiratory difficulties and intermittent slight stridor from birth. Physical examination revealed an underdeveloped infant in acute respiratory distress. He had marked inspiratory retraction of the sternum but no cyanosis. In the suprasternal notch and to its right was a mass, which became obvious during forceful expiration and seemed to collapse or retract into the chest during inspiration. The mass was soft and round and measured $3 \times 2 \mathrm{~cm}$. The trachea seemed to be directed backwards about $45^{\circ}$ in this region. Within the chest many crackles were heard. There was a right-sided hydrocoele. All laboratory examinations were negative.

\footnotetext{
'Present address: The Pediatric Radiology Unit, Beilinson Medical Center, Petah Tiqva, Israel

${ }^{2}$ Francis Sibson, English anatomist, 1814-76
}

After recovering from his respiratory distress, which was thought to be due to croup, the infants was sent for radiological investigation with the referring diagnosis of laryngocoele. Plain films showed a gas-containing structure in front of and $\stackrel{\square}{\varnothing}$ to the right of the trachea just above the supra- $\overrightarrow{\vec{B}}$ sternal notch. The trachea seemed to be displaced $\frac{0}{3}$ backwards and slightly narrowed (Fig. 1). The

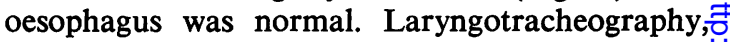
done with fluoroscopy under general anaesthesia, failed to show a communication with this struc-o ture. When positive endotracheal pressure was applied, the structure bulged up into the supra-clavicular region; with negative intrapleural 3 . pressure (spontaneous inspiration) the bulge dis-ণ̊ appeared. A smaller structure of the same nature was also seen on the left (Fig. 2). The diagnosiso of bilateral protrusion of the lung apices through Sibon's fascia, more marked on the right, waso made.

The infant was discharged. Three years later physical examination and radiographs of the 0 chest and neck revealed no protrusion of lung orN any other abnormalities.

CASE 2

A 3-month-old boy was admitted to hospitale because of bloodstained diarrhoea, which later cleared after a liquid diet. Bilateral cervicalo lymphadenopathy was present. In the region of the lower neck there was greater fullness when the baby exhaled and during crying. A small right
inguinal hernia was present.

A lateral radiograph of the neck showed an in-o 


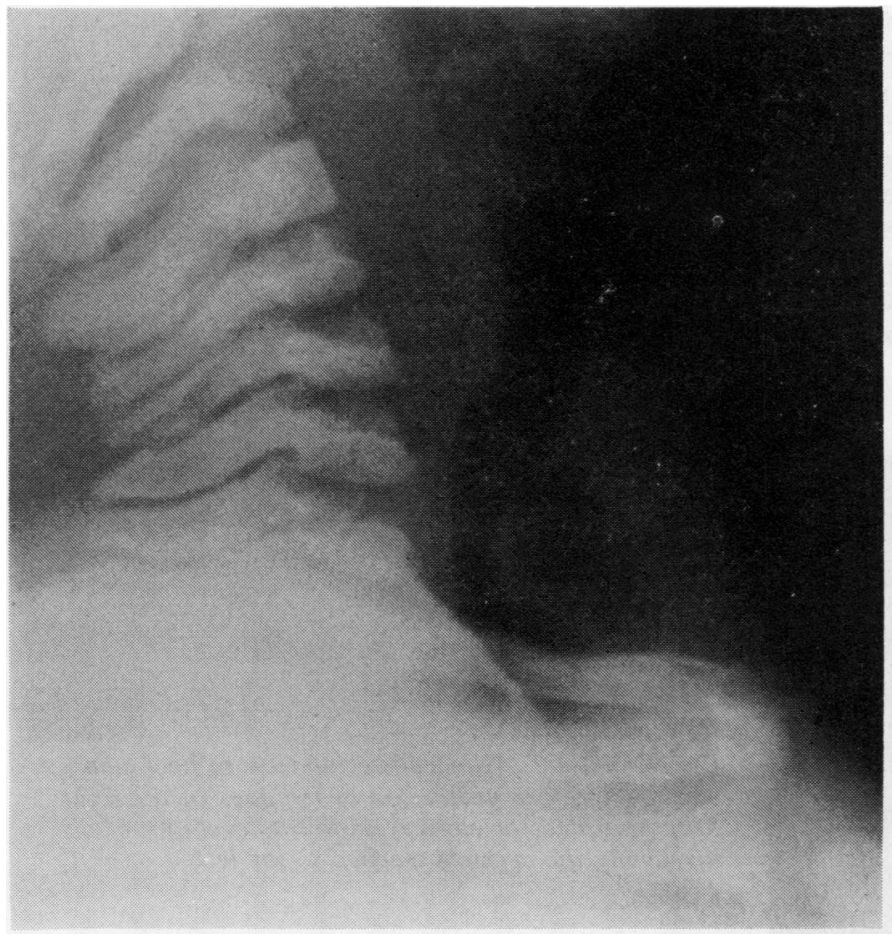

Fig. 1 Case 1. Lateral view of neck and upper chest. There is a transradiant structure in front of the trachea low in the neck pushing the superficial soft tissue forward. The trachea may be slightly displaced and narrowed.

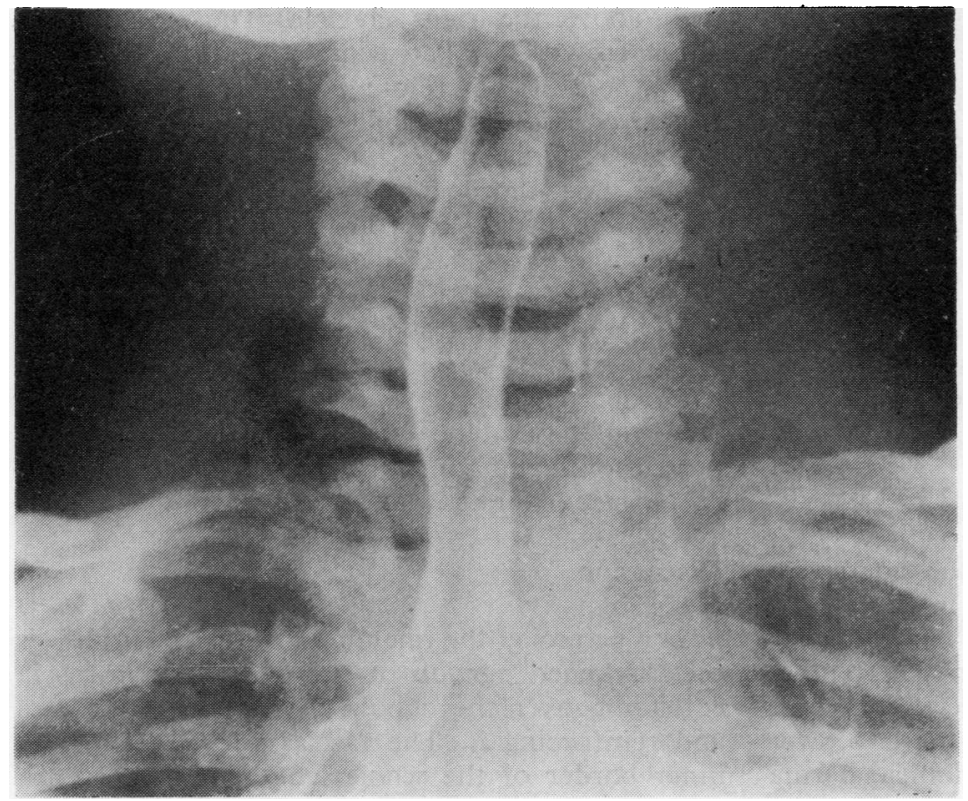

Fig. 2 Case 1. Anteroposterior view of neck and upper chest during a laryngotracheobronchogram. The larynx, trachea, and bronchi are normal. The film shows the right-sided apical lung protrusion and also a small protrusion on the left. 
crease in soft tissue between the posterior margin of the air column and the anterior margin of the cervical spine. This was later shown to represent aberrant thyroid tissue. At the base of the neck, overlying the lower trachea, was an oval transradiancy (Fig. 3). Fluoroscopy showed 'herniation' of the apex of the right lung up to the level of the subglottic region, prominent during expiration (Fig. 4) but disappearing during inspiration. The hypopharynx and oesophagus were fluoroscopically normal.

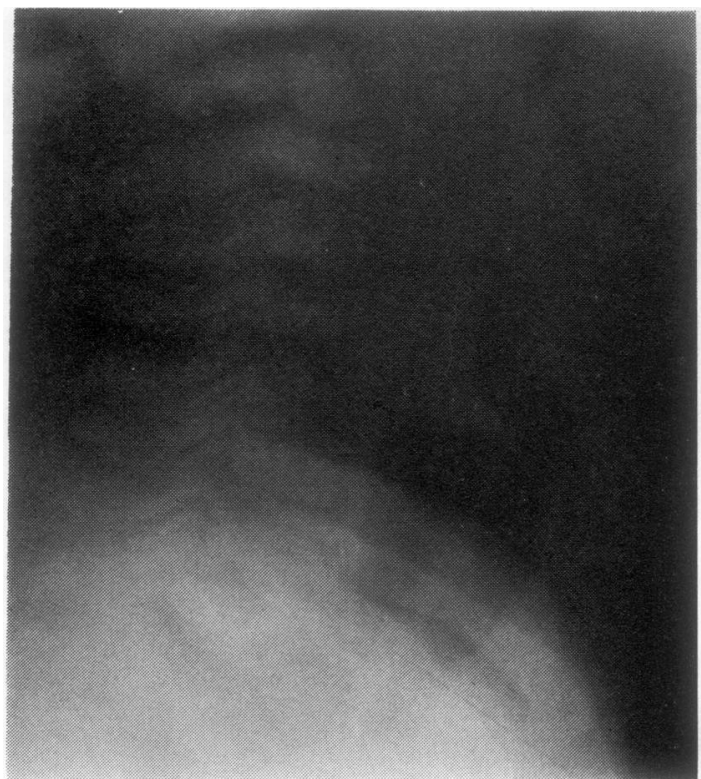

Fig. 3 Case 2. Lateral view of neck. An oval transradiancy overlies the lower extrathoracic segment of the trachea and the retrotracheal tissues. The increased soft tissue interval between the trachea and the cervical spine was later found to be due to aberrant thyroid tissue.

The patient was discharged. Physical examination and chest radiographs two years later revealed no protrusion of the lung or any other positive findings.

\section{CASE 3}

An 8-month-old girl was brought to the emergency room because of upper respiratory infection and high fever.

Physical examination revealed cervical lymphadenopathy. No masses were palpable in the neck. Breath sounds were diminished over the left lower lobe. The heart was normal. An umbilical hernia

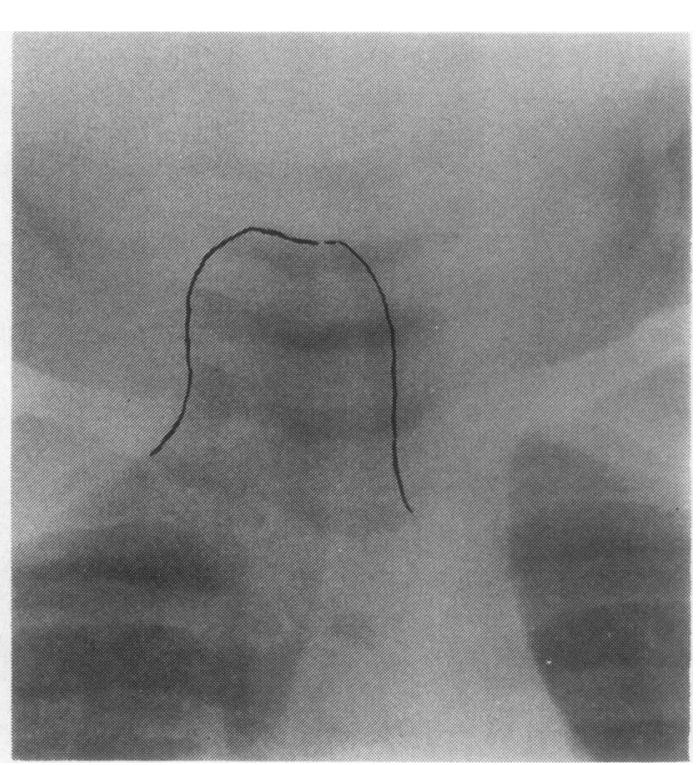

Fig. 4 Case 2. Anteroposterior view of neck and chest. There is a protrusion of the apex of the right lung (outlined for clarity) up to the level of C4, displacing the cervical trachea to the left.

was present. Apart from a leucocytosis, labora- $\overrightarrow{\vec{B}}$ tory examinations were negative.

Radiographic examination of the chest revealed pneumonia in the left lower lobe. In its extra-o thoracic segment the trachea was displaced to the left by an elongated, oval transradiancy, extending 응 high above the right clavicle. The trachea was $\tilde{\times}^{\circ}$ not narrowed. Six-per-second $105 \mathrm{~mm}$ cinefluoro- $\dot{\sigma}$ scopic spot films were obtained during one respiratory cycle while the child was crying vigorously. $\delta$ During inspiration the lung apices extended only to the first thoracic vertebra (Fig. 5a). During 의 expiration there was protrusion of the right lung $>$ into the neck and displacement of the cervicalo trachea to the left (Fig. 5b). The mediastinum was in the midline. No tracheal narrowing was evident. $\%$

The patient was discharged after recovering $N$ from her pneumonia. She was admitted later for ${ }_{\mathcal{W}}^{N}$ repair of the umbilical hernia. On this occasion noo protrusion of lung into the neck could be detected by physical examination or radiography.

\section{Discussion}

Sibson's fascia, the membrana suprapleuralis, is $\stackrel{\overparen{\Omega}}{\mathbb{Q}}$ the thickened portion of the endothoracic fascia $\stackrel{\vec{D}}{\Phi}$ extending over the cupola of the parietal pleura $\frac{\Omega}{0}$ and reinforcing it. The fascia is attached to the inner border of the whole length of the first ribo 


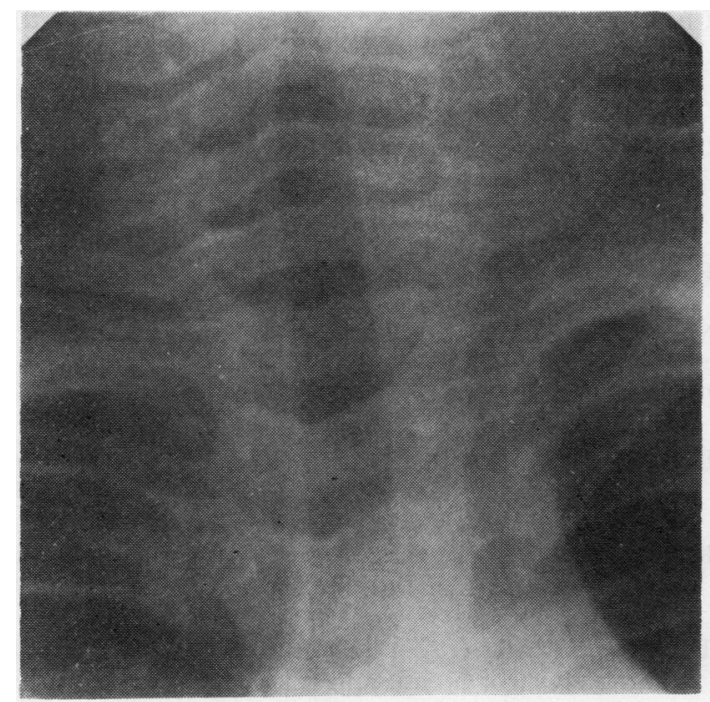

(a)

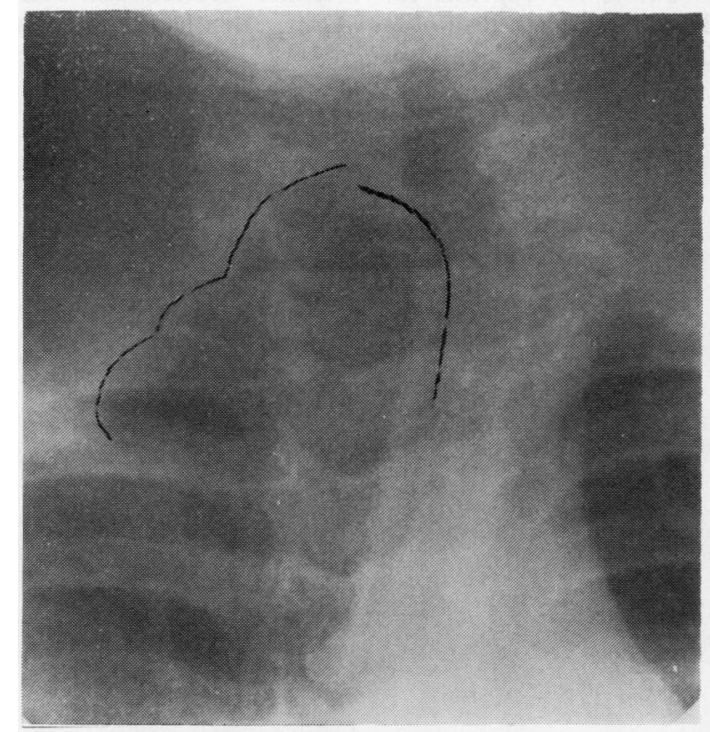

(b)

Fig. 5 Case 3. Spot radiographs obtained during fluoroscopy: (a) during inspiration (negative intrapleural pressure), no herniation is identified; (b) during vigorous crying (positive intrapleural pressure, glottis nearly closed). Typical apical lung protrusion (outlined for clarity) on the right.

and the first costal cartilage and to the transverse process of the seventh cervical vertebra. It blends into the parietal pleura. Sibson's fascia is limited posteriorly and laterally by the vertebral column, first rib, levator scapulae muscle, and scalenus medius muscle. Medially, it is bordered by the superior mediastinal structures, including the trachea and great vessels, while anteriorly it is limited by the scalenus anterior and the sternocleidomastoid muscles (Hayek, 1960; Pernkopf, 1963; Bronsther et al., 1968; Cunningham and Peters, 1969).

During quiet respiration the apex of the lung lies at the level of the upper border of the posterior part of the first rib. But, if intrapleural pressure is increased and Sibson's fascia is less resistant than usual, the lung apex may protrude into or through the fascia and rise a variable distance into the neck.

The cause for protrusion of the apex of the lung is unknown; perhaps it is due to some local variation in development. Two of our patients (cases 2 and 3) had hernias elsewhere, and the third had a hydrocoele, which suggests generalised fascial laxity. Other congenital anomalies, such as cleft palate and cleft lip (Palazzo and Garrett, 1951) and the cri du chat syndrome (Cunningham and Peters, 1969), have been described in the presence of apical lung protrusion. The protrusion may be unilateral (cases 2 and 3 ) or bilateral (case 1). The right side is more frequently involved than the left.

Protrusions of the apex of the lung are easily identified on chest radiographs (Fig. 4) or on neck radiographs, which include the apices of the lung (Fig. 1). Radiographs obtained in the apicallordotic position may exaggerate the height of the lung apex. On ordinary frontal views the protruded lung is seen as an oval, elongated transradiancy (Fig. 4). In the lateral view the protruded lung projects anterolateral or posterolateral to the trachea at the base of the neck (Figs 1, 3, and 5). Fluoroscopy during a respiratory cycle will show an increase in size during expiration, especially during crying or coughing (Fig. 5b); the transradiant area retreats into the chest during inspiration (Fig. 5a). There is never any shift of the intrathoracic trachea, the oesophagus, or other mediastinal structures. In infancy, during expiration, the normal lateral deviation of the trachea just above the thoracic inlet is nearly always to the side opposite the aortic arch (Chang et al., 1970). Lung protrusions seem to act as masses, however, at least in respect to deviation of the cervical trachea. The trachea will often shift away from the protrusion, and in right-sided protrusion the tracheal deviation is towards rather than away from the aortic arch (Fig. 4). When the protrusion is bilateral, the trachea deviates towards the smaller protrusion (Fig. 2), or there may be no 
deviation at all. In the lateral projection, the cervical trachea may be slightly narrow (Fig. 1), especially if the lateral radiograph of the neck is obtained during expiration.

Since it requires no surgical intervention during infancy and usually disappears during childhood, lung protrusion through Sibson's fascia must be distinguished from more alarming transradiancies such as laryngocoeles, pharyngocoeles, and rupture of the pyriform sinus. If excision is attempted disaster may follow. Tracheostomy also carries a substantial risk of pneumothorax when unrecognised protrusion of the lung is present. However, radiography and fluoroscopy of the neck and the chest, together with an awareness of the entity, will promptly lead to the correct diagnosis.

We thank Dr. Edward B. D. Neuhauser and John A. Kirkpatrick for their helpful comments.

\section{References}

Bronsther, B., Coryllos, E., Epstein, B., and Abrams, M. W. (1968). Lung hernias in children. Journal of Pediatric Surgery, 3, 544-550.
Chang, L. W., Lee, F. A., and Gwinn, J. L. (1970). Normal lateral deviation of the trachea in infantso and children. American Journal of Roentgenologyo and Radium Therapy, 109, 247-251.

Cunningham, D., and Peters, E. R. (1969). Cervical hernia of the lung, associated with the cri du chat syndrome. American Journal of Diseases of Chil-in

dren, 118, 769-771.
Hayek, H. (1960). The Human Lung. Hafner, New: York.

Munnell, E. R. (1968). Herniation of the lung. Annalso of Thoracic Surgery, 5, 204-212.

Palazzo, W. L., and Garrett, T. A. (1951). Cervical hernia of the lung. Radiology, 56, 575-576.

Pernkopf, E. (1963). Atlas of Topographical andit Applied Human Anatomy, Volume 1. W. B. Saunders, Philadelphia.

Reinhart, H. A., and Hermel, M. B. (1951). Hernia- $-\supset$ tion of the lung in the cervical region. Radiology, 57, 204-207.

Thompson, J. S. (1976). Cervical herniation of the lung. Report of a case and review of the literature. Pediatric Radiology, 4, 190-192.

Requests for reprints to: Michael Grunebaum, MD, The Pediatric Radiology Unit, Beilinson Medicalo Center, Petah Tiqva, Israel. 